\title{
The Influence of Time of Diagnosis on Neurodevelopmental Outcomes of Complicated Monochorionic Pregnancies
}

\author{
Longhurst $\mathrm{E}^{1 *}$, Smoleniec J ${ }^{2}$ and Stack $\mathrm{J}^{2}$ \\ ${ }^{1}$ Department of Neurology, Australia \\ ${ }^{2}$ Liverpool Hospital, Australia \\ *Corresponding author: Longhurst E, Department of Neurology, Australia
}

\section{ARTICLE INFO}

Received: 蔧 March 26, 2019

Published: 㓞 April 09, 2019

Citation: Longhurst E*, Smoleniec J, Stack J. The Influence of Time of Diagnosis on Neurodevelopmental Outcomes of Complicated Monochorionic Pregnancies. Biomed J Sci \& Tech Res 16(5)-2019. BJSTR. MS.ID.002922.

Keywords: Twin; Monochorionic; Diamniotic; Complications; Long-Term Neurodevelopmental Outcomes; Bayley's Scale of Infant Development Third Edition (BSID-III)
ABSTRACT

Background: There is a paucity of data regarding the relationship between time of diagnosis of monochorionic twins with complications and the neurodevelopmental outcomes of these twins.

Objective: The aim of this study was to present the effect of time of diagnosis on neurodevelopmental outcomes of monochorionic twins diagnosed with complications, namely TwinTwin Transfusion Syndrome (TTTS), pre-TTTS, selective Intrauterine Growth Restriction (sIUGR) or Twin Anaemia Polycythemia Syndrome (TAPS).

Methods: A prospective cohort study was conducted, comparing the neurodevelopmental outcomes of pre and post 28-week diagnosis of monochorionic complications. The study analysed the data of monochorionic twin pregnancies diagnosed at Liverpool Hospital, from 2009 until 2018. Outcomes were compared using independent samples t-tests, Chi-square analysis and the Fisher's Exact Test.

Results: Significant differences in motor and language outcomes were observed between the pre and post 28-week groups; of $44.74 \%$ and $21.40 \%$ respectively. Categorical analysis revealed significance for motor outcomes between the pre and post 28-week groups ( $\mathrm{p}=0.016)$, and language outcomes in the numerical group ( $\mathrm{p}=0.009)$. Both results had higher neurodevelopmental means for the post 28 week group.

Conclusion: The post 28-week group was shown to perform better neurodevelopmentally than the pre 28-week group in language and motor outcomes. This confirms the justification of regular monitoring of monochorionic pregnancies.

\section{Introduction}

Twin pregnancies carry an increased risk of complications relative to singleton pregnancies [1,2]. The majority of twins (approximately 80\%) are Dichorionic Diamniotic (DCDA) pregnancies. Twins that are Monochorionic Diamniotic (MCDA) have an even greater risk of serious complications when compared with DCDA, of $23 \%$ vs $4 \%$ [3,4]. Approximately $20 \%$ of twins are monochorionic and whilst the majority of monochorionic twins have individual amniotic sacs (MCDA), [5] 1\% of monochorionic twins have only one amniotic sac and are known as Monochorionic Monoamniotic pregnancies (MCMA) [6,7]. Associated neurological effects of complications during pregnancy may have a profound longterm effect on an individual's health [8-10]. Monochorionic twins are 2-3 times more likely than dichorionic twins to be delivered before 32 weeks and have higher rates of congenital abnormalities and an increased risk of intrauterine (9times more likely than singletons) and neonatal death (IUD, NND) $[2,11,12]$. Even when prematurity and low birth weight is accounted for, monochorionicity still increases the risk for poor neurodevelopmental outcomes [13].

According to a cohort study, $41 \%$ of monochorionic pregnancies had neurodevelopmental concerns [14] with no pre-natal complications identified and who delivered in the $3^{\text {rd }}$ trimester. The factors referenced as an explanation were very low birth weight, monochorionic complications, antenatal and postnatal injury and prematurity $[7,10,15]$. According to a prospective cohort study of monochorionic and dichorionic twins, MCDA twins had higher rates of cerebral palsy than DCDA as a result of monochorionic specific complications [13]. The commonest complication in monochorionic twins is Twin-Twin Transfusion Syndrome (TTTS), which approximately $10-15 \%$ of MCDA twins develop [16]. Clinicians use the Quintero Staging System to rank 
TTTS in terms of severity, Stage 1 being the least and Stage 4 the most severe [17]. Other complications examined in this study include selective Intrauterine Growth Restriction (sIUGR) and Twin Anaemia Polycythemia Sequence (TAPS ), which are peculiar to monochorionicity [18]. These complications are thought to relate directly to the Twin-Twin Transfusion environment. There are 4 treatment options for TTTS; fetoscopic laser surgery (dividing the placenta to disconnect circulations), amniodrainage (removal of excess amniotic fluid), conservative (close monitoring throughout pregnancy) [19] and delivery.

Termination is also an option. Laser is the preferred intervention as it has lower rates of morbidity, [20] but amniodrainage may be used for Stage 1, or symptomatic polyhydramnios [21]. Generally, conservative treatment has better outcomes; but this is because it is used for amniotic fluid discordance and Stage 1 TTTS pregnancies [22]. TTTS is a condition peculiar to monochorionic pregnancies that most commonly develops between 15-26 weeks of gestation. Monochorionic placenta fetuses are at risk of unequal placenta share and volume imbalance associated with placental vascular anastomoses which connect both circulations [23-25]. The complications of this include size discordancy, TTTS, TAPS and Amniotic Fluid Index (AFI) discordancy. TAPS results from chronic monochorionic fetofetal transfusion, resulting in large haemoglobin differences between twins [26]. Due to the haematological and haemodynamic instability that is associated with TTTS and TAPS, blood flow to the brain can be affected, resulting in significant neurological effects [13]. Approximately $20 \%$ of TTTS twins bear

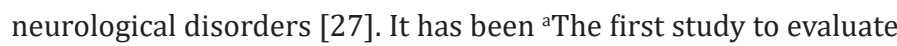
the long-term neurodevelopmental outcomes in TTTS survivors who developed TAPS after laser surgery concluded that the rates of poor neurodevelopmental outcomes were comparable to those with TTTS who were treated with laser therapy (see 18 in reference list) suggested that up to $15.4 \%$ of infants with TTTS are diagnosed with cerebral palsy after amniodrainage treatment, and 8.5\% when managed by fetoscopic selective laser coagulation of anastomoses (FSLCAS) [21].

Disabilities that are associated with TTTS include cerebral palsy, cognitive defects and attention deficit disorder. They can also be isolated, which means that they are often misdiagnosed, apart from when a child undergoes a neurodevelopmental screening $[28,29]$. Neurodevelopmental outcomes are an important sequalae of the complications that result from MCDA twin pregnancies. Numerous studies have specifically investigated the extent of poor neurological outcomes on twins with TTTS, $[17,19,30]$ but few have compared the results of twins diagnosed before 28 weeks with after 28 weeks. There are significant gaps in knowledge regarding how far TTTS can progress without being symptomatic [31] and which gestational parameters have better outcomes. This study aims to clarify the outcomes of complicated monochorionic twins diagnosed in the $3^{\text {rd }}$ trimester, as there is a paucity of research on this topic [20]. Whilst it is well understood that there are poor neurodevelopmental outcomes in twins with monochorionic complications, the exact nature of these neurodevelopmental effects is not as well understood; whether it is cognition, language or motor function that is most affected. To identify the neurological effects of monochorionic complications, neurodevelopmental assessments at
8 months and 2 years of age provide important observations about neurological deficits [22]. The Bayley's Scale of Infant and Toddler Development (BSID-III) is currently the most research appropriate neurodevelopmental assessment available [32].

\section{Methods}

This was a single-centre prospective cohort study of 53 monochorionic twins who attended the Liverpool Hospital FetoMaternal Unit (FMU) and were then followed up at 8 months and 2 years at the Liverpool and Campbelltown Hospital Rainbow Clinic. It retrospectively reviewed a prospectively collected dataset; every MCDA twin pregnancy with complications associated with monochorionicity from 2009 until 2015 was approached during gestation for the longitudinal study. From February 2010 until August 2018, neurodevelopmental outcomes of each twin were evaluated using the Motor Assessment of Infants (MAI) and Rossetti Language assessments at 8 months, and the BSID-III at 2 years. Corrections to gestational age for prematurity were made. Inclusion criteria for the project included a positive diagnosis of TTTS, pre-TTTS or TAPS and consent to have personal data included in the FMU administrative system. Pre-TTTS was defined as AFI discordancy with both bladders present. Each participant was required to be involved in the study for a minimum of $2 \frac{1}{2}$ years.

Liverpool Hospital is a tertiary referral centre in the South Western Sydney Local Health District. The FMU services this population with tertiary prenatal services for approximately 11,000 pregnancies per year in SWSLHD. There are approximately 25 monochorionic pregnancies diagnosed per year at the Liverpool FMU. Data regarding the antenatal details of the participants was sourced from the internal database of the FMU. Enrolment for this study was discussed after diagnosis of monochorionic complications during pregnancy and consent obtained after delivery. Participants were informed of the 8 month and 2-year neurodevelopmental assessments, and the option for further assessments as well.

\section{Diagnosis of TTTS During Pregnancy}

Regular monitoring of monochorionic pregnancies is recommended because of the increased risks associated with these pregnancies. Following the first visit at which the obstetrician diagnosed monochorionicity with an ultrasound (noting placental number, the " $\mathrm{T}$ " sign and intertwin membrane thickness), counselling and management plan was discussed, which entails fortnightly monitoring [33,34]. This is ideally late in the 1st trimester. At these fortnightly assessments, ultrasound was performed to quantify fetal bladders, amniotic fluid indices, umbilical artery and Middle Cerebral Artery (MCA) Doppler values, fetal biometry, Estimated Fetal weight and growth measurements for both twins [31]. Diagnosis with TTTS was made when the stated parameters fitted the clinical picture of TTTS; oligo-polyhydramnios, doppler abnormalities (Middle Cerebral Artery Peak Systolic Velocity (MCAPV), umbilical artery and ductus venosus) and significant fetal weight differences over a significant period of time.

\section{Tests used to Assess Neurodevelopmental Function at 8 Months}

The Motor Assessment for Infants (MAI): The MAI score is used to assess motor function in infants with a low birthweight 
in their first year of life. It assesses primitive reflexes, automatic reactions, muscle tone and volitional movements. Only scores that are below 16 are concerning, and those above are not concerning. The test has a sensitivity for CP of $73.5 \%$ [35]. It is considered an appropriate test to conduct to assess motor function in this age group; as correlations between the MAI assessment at 4 months were highly significant when partnered with the BSID-III at 2 years $(\mathrm{p}<0.001)$ [36].

Tests used to assess Neurodevelopmental Function at 2 Years

Rossetti Language: The Rossetti Language test has the advantage of being suitable for those who are from a non-English speaking background and can be used for those between $0-3$ years old. Rossetti language scores are given as age brackets that correspond with levels of development, as a few months leeway is given for language outcomes [35,34]. It is often used in conjunction with other tests like the BSID-III because it is designed as a broader assessment of language by assessing both language comprehension and expression, interaction attachment, language pragmatics and play [37].

Gross Motor Function Classification System (GMFCS): THE GMFCS score was used in this study to identify cases of Cerebral Palsy (CP). This test has 5 levels of classification that tests gross motor function based on self-initiated movements. It is tested at ages 0 -18. It is considered the gold standard for predicting $\mathrm{CP}$, as the test has a sensitivity of $94 \%$ and a specificity of $87 \%$ [38].

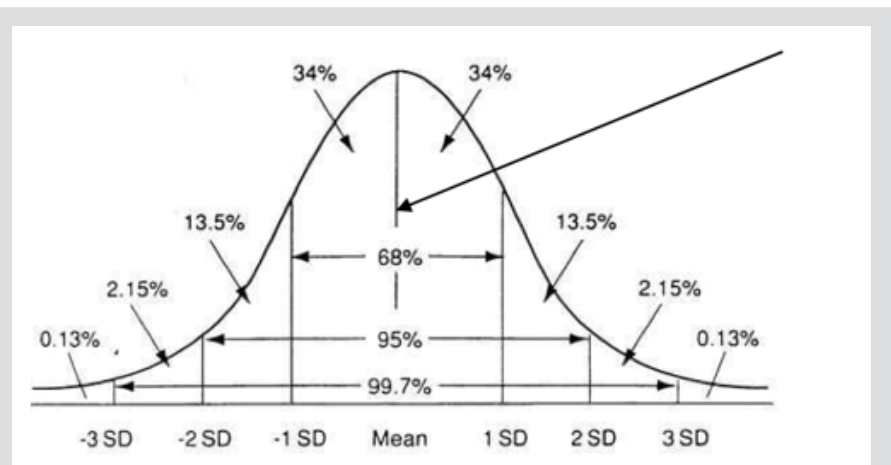

Figure 1: The bell curve: these percentiles are used to score and compare Neurodevelopmental results from the BSID-III.

The BSID-III: The BSID-III is a normative assessment that examines cognitive function, motor function, language function, social and emotional and adaptive behaviour. It uses an index mean of scores of $100(+/-15)$, and for this study, a score of 75 or below was considered severe impairment, whilst a score from 75-85 was mild impairment, and a score above 85 was clinically non-concerning [39]. It uses a series of tests to quantify problem solving ability, object identification, language expression and comprehension, fine and gross motor function, and social and behavioural functioning [40]. The BSID-III uses two scores; a composite score which adds all the individual test scores together, and a bell curve score to compare the outcomes of infants of similar age brackets with each other [32]. Each particular assessment is scored and then these scores are added together to achieve a composite score which is then converted into a scaled score. The scaled score is calculated using a bell curve (Figure 1).

\section{Statistical Analysis}

Results were collected from both the 8 month and 2-year assessments. The 2-year assessments were analysed more comprehensively, because numerous past studies have shown that data collected later in childhood is more representative of true outcomes [41]. Due to the small sample size, a primarily descriptive approach was used (means, proportions and standard deviations). A confidence interval of $95 \%$ was assumed for all tests. For the numerical scores, independent t-tests were performed. Statistical significance was given at $\mathrm{p}<0.05$. For the categorical neurodevelopmental scores (concerning, borderline and good), the Chi-Square test and Fisher's Exact Test was used in a broad comparison of the pre and post 28-week groups, gestational age and birthweight. Both the Chi-Square test and Fisher's Exact Test were used due to the small sample size. Effect sizes were calculated using Cohen's d. Statistical analysis of the results was performed using IBM SPSS 25.0 statistical software.

\section{Results}

A cohort of 32 pregnancies, with 53 surviving babies, were recruited from the FMU. Initially, 72 fetuses were enrolled in the group, but 4 of these pregnancies did not participate in the neurodevelopmental study and so were not included. Unfortunately, 10 of the fetuses passed away, either in utero or neonatally. One of the pregnancies was not included in the final analysis due to diagnosis with Twin Reversed Arterial Perfusion Sequence (TRAP). This group was then followed for two years, whence upon they completed their 24-month BSID-III assessment (the earliest neurodevelopmental assessment in February 2010 and the latest in August 2018). This cohort can be seen in Figure 2 and consisted of a variety of monochorionic complications. 4 participants were diagnosed with monochorionic complications before 28 weeks but were delivered before 28 weeks (Figure 3), and so the data size available for this comparison was 49 out of the 53 participants. These participants were excluded because it is not possible to compare results of twins diagnosed before and after 28 weeks, as each participant needed to have experienced the post 28-week period by definition. 


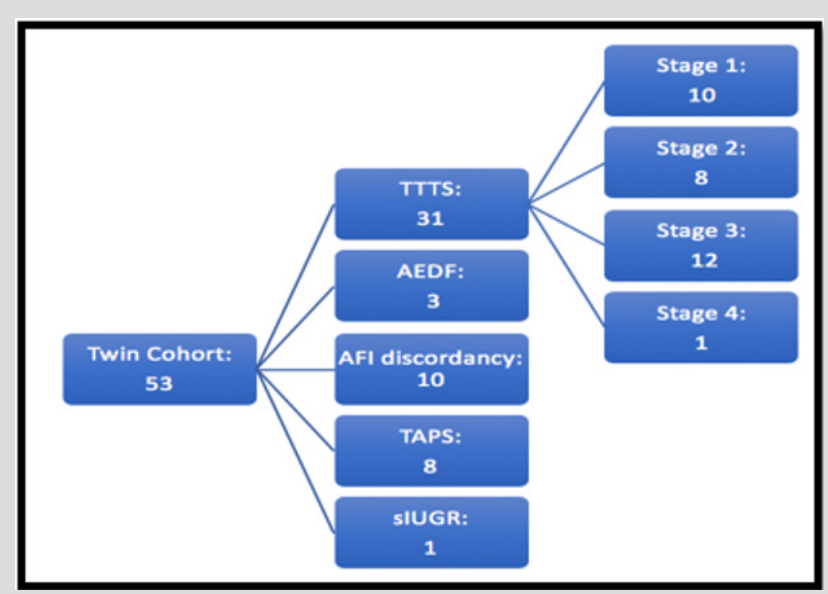

Figure 2: Breakdown of the cohort.
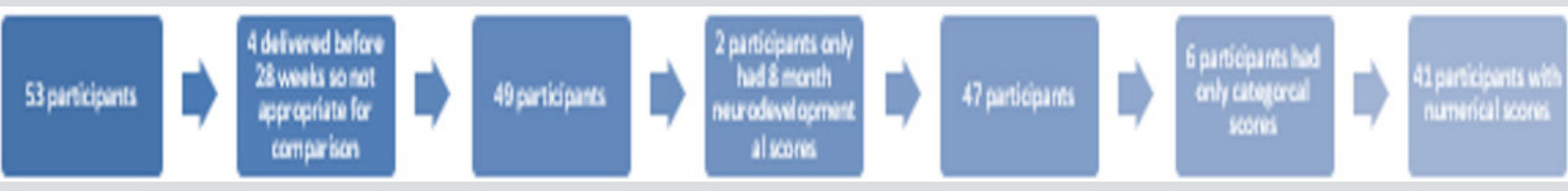

Figure 3: Explanation of cohort numbers.

Moreover, two participants only had results for their 8-month assessment. Due to 6 participants only having categorical neurodevelopmental scores, the cohort assessed for their numerical results consisted of the neurodevelopmental assessments at 2 years was 41 participants. Categorical assessments for 6 participants received either a good, borderline or concerning outcome based on the judgement of the assessor(s), rather than the BSID-III composite score. These scenarios occurred as a result of non-compliance during the testing. Of the 41 participants, 27 were diagnosed before 28 weeks and 14 were diagnosed after 28 weeks. Further, the discrepancy in numbers between the different components of the neurodevelopmental assessments is due to incomplete test completion by the participant.

\section{Pregnancy Characteristics}

The average BMI of the mothers was 26.18 (SD+/-6.92), and the mean age was 30.20 years, with $12.50 \%$ of mothers identifying as smokers, and $6.25 \%$ as drinkers of alcohol. The main commonest method of conception was spontaneous (87.50\%). Caesarean was the most common delivery method $(71.88 \%)$, with vaginal delivery at $28.13 \%$. Complications during pregnancy included light bleeding in the first trimester (15.63\%), gestational diabetes $(6.25 \%)$, short long bones (3.13\%), post-partum endometritis (3.13\%) and cord hemangioma (3.13\%). The mean birthweight of this group was 1681.8g (SD+/- 662.50), and the mean gestational age was 32.3 (SD+/- 4.06). There were 17 male twin pairs and 15 female twin pairs. The median first APGAR score was 8. There are notable cohort complications included in the table below; Patent Ductus Arteriosus in 7 participants, and 2 cases of brain injury. The cases of anaemia and polycythemia were attributed to the TAPS participants. The high number of infectious diseases (21/53) is expected in a premature twin cohort. ${ }^{b}$ Appearance, Pulse, Grimace,
Activity, Respiration. The majority of the twins in the study were diagnosed with one of the 4 Quintero stages of TTTS. $18.87 \%$ were diagnosed with pre-TTTS (characterised by AFI discordance or umbilical artery discordance), 1.89\% with sIUGR and 15.09\% with TAPS (which is considered a specific type of TTTS). In this cohort, 2 of the TAPS cases were post-laser, and the other 6 were not. Of the TTTS diagnoses, $24.53 \%$ of the entire cohort were Stage $1,15.10 \%$ were Stage 2, 22.64\% were Stage 3 and 1.89\% were Stage 4 .

'Insult proceeding laser treatment.

\section{Neurodevelopmental Outcomes}

\section{Developmental concerns at 8 months}

At 8 months, assessments about language and motor skills can be effectively made. For language expression, the median was in the 6-9-month range, which is the expected range for 8 months. However, a concerning number of children only achieved the $0-3$ month and 3-6-month language range (12 for language expression and 14 for language comprehension). To compute the Rossetti language scores in SPSS, each Language Range was allocated a sequential number $(0,1,2,3)$. The Pearson Chi-Square test revealed no statistical difference between the pre and post 28-week groups for Language Expression (p-value=0.345), and no statistical difference for Language Comprehension ( $p$-value=0.065). This can also be seen in Tables $1 \& 2$.

${ }^{\mathrm{d}} \mathrm{A}$ total of 46 participants completed all sections of the language expression assessment,

${ }^{\mathrm{e}} \mathrm{A}$ total of 49 participants completed all sections of the language comprehension assessment,

${ }^{\mathrm{f}} \mathrm{A}$ total of 42 participants completed all sections of the MAI. 
Table 1: Cohort Complications.

\begin{tabular}{|c|c|}
\hline Complications & \\
\hline \multicolumn{2}{|c|}{ Complications related to Prematurity } \\
\hline Necrotising Enterocolitis & 2 \\
\hline Spontaneous Intestinal Perforation & 1 \\
\hline Bowel ischaemia and resection & 1 \\
\hline $\begin{array}{l}\text { Persistent Ductus Arteriosus } \\
\text { (PDA) }\end{array}$ & 7 \\
\hline Bradycardia and desaturations & 3 \\
\hline Herniation & 3 \\
\hline $\begin{array}{l}\text { Respiratory Distress Syndrome } \\
\text { (RDS) }\end{array}$ & 4 \\
\hline Tracheoesophageal fistula & 1 \\
\hline Pulmonary artery stenosis & 1 \\
\hline Chronic lung disease & 3 \\
\hline Infectious disease & 21 \\
\hline Retinopathy of prematurity & 4 \\
\hline Asphyxia/brain injury & 2 \\
\hline $\begin{array}{l}\text { Intraventricular haemorrhage } \\
\text { (Grade 1) }\end{array}$ & 2 \\
\hline Seizures & 1 \\
\hline Global Brain Insult & 1 \\
\hline Ventriculomegaly & 1 \\
\hline Right basal ganglia infarction & 1 \\
\hline Altered renal function & 1 \\
\hline Nephrocalcinosis & 1 \\
\hline $\begin{array}{c}\text { Acute renal failure and } \\
\text { hyperkalaemia }\end{array}$ & 1 \\
\hline \multicolumn{2}{|c|}{ Congenital Complications } \\
\hline Conjugated Hyperbilirubinemia & 2 \\
\hline Atrial Septal Defect (ASD) & 1 \\
\hline Cardiomyopathy & 1 \\
\hline Bilateral hydroceles & 1 \\
\hline Hypospadias & 2 \\
\hline Bilateral undescended testicles & 1 \\
\hline \multicolumn{2}{|c|}{ Complications related to TTTS } \\
\hline Fetal anaemia & 10 \\
\hline Thrombocytopaenia & 8 \\
\hline Polycythemia & 8 \\
\hline Hydrops & 2 \\
\hline Absolute neutropenia & 1 \\
\hline \multicolumn{2}{|c|}{ Maternal and pregnancy complications } \\
\hline Pre-eclampsia & 1 \\
\hline Cervical varicosities & 1 \\
\hline Post-partum endometritis & 1 \\
\hline
\end{tabular}

Table 2: 8 month Language and Motor Outcomes

\begin{tabular}{|c|c|c|c|}
\hline $\begin{array}{c}8 \text { month } \\
\text { neurodevelopmental } \\
\text { outcomes }\end{array}$ & $\begin{array}{l}\text { Diagnosis } \\
\text { Pre } 28 \\
\text { weeks }\end{array}$ & $\begin{array}{l}\text { Diagnosis } \\
\text { Post } 28 \\
\text { weeks }\end{array}$ & $\begin{array}{l}\text { Pearson Chi- } \\
\text { Square Statistic } \\
\text { and p-value }\end{array}$ \\
\hline \multicolumn{4}{|c|}{ Language Expression } \\
\hline 0 to 3 months & 3 & 4 & \\
\hline 3 to 6 months & 4 & 1 & \\
\hline 6 to 9 months & 23 & 10 & \\
\hline 9 to 12 months & 1 & 0 & \\
\hline \multicolumn{3}{|c|}{ Statistics } & $\begin{array}{c}3 . .741 \\
\text { (p-value }=0.345)\end{array}$ \\
\hline \multicolumn{4}{|l|}{$\begin{array}{c}\text { Language } \\
\text { Comprehension }\end{array}$} \\
\hline 0 to 3 months & 4 & 4 & \\
\hline 3 to 6 months & 6 & 0 & \\
\hline 6 to 9 months & 24 & 11 & \\
\hline 9 to 12 months & 0 & 0 & \\
\hline \multicolumn{3}{|c|}{ Statistics } & $\begin{array}{c}5.461 \\
\text { (p-value }=0.065 \text { ) }\end{array}$ \\
\hline \multicolumn{4}{|l|}{ MAI } \\
\hline Below and equal to 16 & 21 & 14 & \\
\hline Above 16 & 7 & 0 & \\
\hline \multicolumn{3}{|c|}{ Statistics } & $\begin{array}{c}4.200 \\
(p-v a l u e=0.044)\end{array}$ \\
\hline
\end{tabular}

\section{MAI}

The MAI results identified 2 participants who were likely to have cerebral palsy; these participants then underwent the GMFCS, which gave a positive diagnosis of cerebral palsy (GMFCS 1). The mean score in the motor assessment was 9.6 (SD+/-8.0). MAI scores $>16$ (of which there were 7 , (Figures $4 \& 5$ ) is indicative of potential motor complications in the future, such as cerebral palsy (Figure 3 \& Table 3). Interestingly, all of these 7 scores were from the pre 28-week diagnosis group. Categorising MAI outcomes into concerning and good, there was a Pearson Chi-Square value of 4.2, (Table 2), (p-value=0.04), denoting a statistical significance in the pre and post 28-week groups in motor outcomes.

Table 3: Numerical BSID-III results for post and pre 28 week groups.

\begin{tabular}{|c|c|c|c|}
\hline $\begin{array}{c}\text { BSID-III } \\
\text { Components }\end{array}$ & $\begin{array}{c}\text { Mean score for } \\
\text { those Diagnosed } \\
\text { Before 28 weeks }\end{array}$ & $\begin{array}{c}\text { Mean score for } \\
\text { those Diagnosed } \\
\text { After 28 weeks }\end{array}$ & p-value \\
\hline Cognitive & $94.79(+/-14.02)$ & $103.19(+/-16.27)$ & 0.409 \\
\hline Language & $89.00(+/-17.83)$ & $94.55(+/-15.38)$ & 0.587 \\
\hline Motor & $72.63(+/-40.04)$ & $96.13(+/-27.05)$ & 0.016 \\
\hline
\end{tabular}

\section{Developmental Concerns at 2 years}

The 2-year BSID-III scores revealed a concerning number of neurodevelopmental deficits. $45 \%$ of the cohort did not reach age appropriate outcomes for language. Levels of neurological impairment in this group was also significantly high for cognition (25\%), and motor (26\%). 


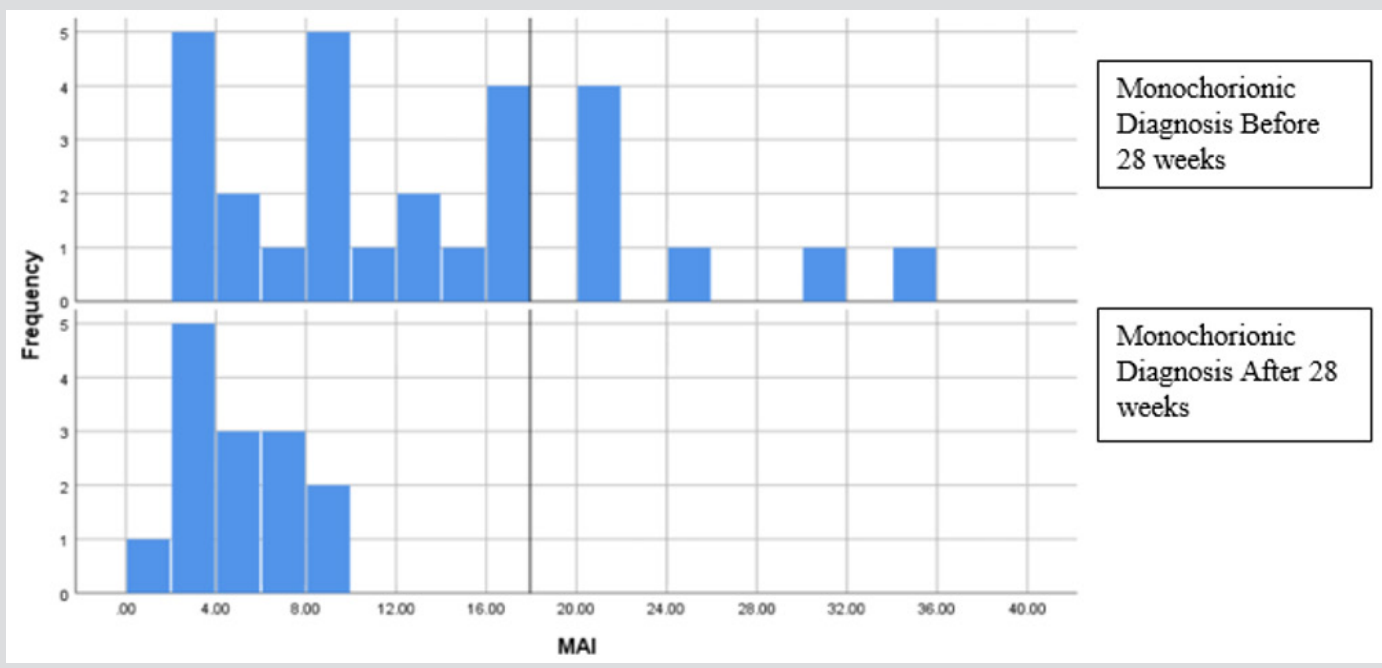

Figure 4: MAI results.

\section{EFFECT OF PREMATURITY ON NEURODEVELOPMENTAL OUTCOMES}

Figure 5: Effect of prematurity on Neurodevelopmental Outcomes.

\section{Diagnosis Pre 28 weeks versus Post 28 weeks}

A comparison between outcomes of twins diagnosed before 28 weeks versus after 28 weeks was performed. For the numerical scores, an independent t-test was performed, with Levene's. 'The vertical line on the $\mathrm{x}$-axis denotes the score ' 16 '; above 16 is a pathological score, and score ' 16 ' and below are non-concerning scores. Test for Equality of Variances providing p-values. The mean results for the pre and post 28-week groups were not statistically significant for cognition or language ( $p>0.05)$, but they were for motor $(p=0.016)$. The Cohen's $d$ for cognition was 0.17 , for language it was 0.26 and for motor it was 0.42 (small sized effects). Interestingly, the post 28-week group had higher mean scores for the motor assessment than the pre 28 week group (Table 3). For the categorical scores, the relationship between time of diagnosis with monochorionic complications and neurodevelopmental outcomes were also examined using the Chi-square test $\left(x^{\wedge} 2\right)$ and the Fisher's Exact Test. This was performed so that all the results could be analysed together (categorical and numerical). Of the 47 participants, 33 were diagnosed before 28 weeks and 14 were diagnosed after 28 weeks. The categories decided upon based on discussion with the assessors of the examination were 'good', 'borderline' and 'concerning'.

This is based on the methods by which the BSID-III scores are described to parents/caregivers/people who are interested in knowing what these scores mean. The categorical results show a statistically significant difference in pre and post 28-week language scores (Table 4). This difference from the results of the purely numerical scores can be explained by the addition of the Rossetti scores, which skewed the results. Thus, this is actually a truer portrayal of the cohort, as all scores are accounted for. 15 of the 33 participants diagnosed before 28 weeks received 'concerning' scores, whilst there were only 3 of the 14 participants diagnosed after 28 weeks with 'concerning' scores. The Pearson Chi-Square test did not show statistical significance for Cognition ( $p=0.535)$, nor for motor $(\mathrm{p}=0.082)$. However, for language the Chi square statistic of 9.469 was significant $(p=0.009)$. Fisher's test showed significance for language $(\mathrm{p}=0.01)$, but not for cognition or motor. There was positive correlation for Language as the Chi-Square and Fisher's Exact Test p-value was $<0.05$ (Figure 6).

Table 4: Categorical Neurodevelopmental outcomes pre and post 28 weeks.

\begin{tabular}{|c|c|c|c|c|}
\hline $\begin{array}{c}\text { Neurodevelopmental } \\
\text { outcomes }\end{array}$ & $\begin{array}{c}\text { Pearson } \\
\text { Chi- } \\
\text { Square } \\
\text { Statistic } \\
\text { (x2) }\end{array}$ & $\begin{array}{c}\text { Pearson } \\
\text { Chi- } \\
\text { Square } \\
\text { p-value }\end{array}$ & $\begin{array}{c}\text { Fisher's } \\
\text { Exact } \\
\text { Test } \\
\text { Statistic }\end{array}$ & $\begin{array}{c}\text { Fisher's } \\
\text { Exact } \\
\text { Test } \\
\text { p-value }\end{array}$ \\
\hline Cognition & 3.329 & 0.165 & 2.744 & 0.246 \\
\hline Language & 9.469 & 0.009 & 8.709 & 0.010 \\
\hline Motor & 4.038 & 0.089 & 3.889 & 0.110 \\
\hline
\end{tabular}




\section{Prematurity Death Rate}

\section{Extreme Prematurity \\ Moderate Prematurity \\ Late Prematurity}

\section{$\begin{array}{lllll}0.00 \% & 10.00 \% \quad 20.00 \% \quad 30.00 \% \quad 40.00 \% \quad 50.00 \% \quad 60.00 \%\end{array}$}

Figure 6: Prematurity Death Rate.

\section{Gestational age and Neurodevelopmental Outcomes}

This cohort was largely biased towards prematurity, due to factors such as twinning and the complications associated with monochorionicity. Statistical analysis of this cohort shows a positive Pearson correlation between gestational age and cognitive scores. The longer the gestation, the higher the level of cognitive scores. However, this is a very small correlation as $r=0.093$. For cognition, the Pearson chi-square value was 14.13 , and there was a p-value of 0.028 , thus statistically significant. The Fisher's Exact Test value was 13.73 and the Fisher p-value was 0.012 . These results favour longer gestation for better cognitive outcomes (Tables 5 \& 6). For language, the Pearson chi-square value was 7.368, and there was

Table 5: Neurodevelopmental outcomes and gestational age. a p-value of 0.268 , thus not statistically significant. The Fisher's Exact Test value was 6.105 and the Fisher p-value was 0.383.These results do not show a significant difference in language. For motor, the Pearson chi-square value was 15.32 , and there was a p-value of 0.020 , thus statistically significant. The Fisher's Exact Test value was 11.068 and the Fisher p-value was 0.041 . There is a clear difference in the motor outcomes of the extremely premature and the term participants, with the extremely premature performing significantly worse than the term participants. ${ }^{\text {h}}$ The time of each neurodevelopmental assessment was corrected for gestational age. As a group, the extremely premature had significantly worse neurodevelopmental results, with $75 \%$ having concerning outcomes.

\begin{tabular}{|c|c|c|c|c|c|c|}
\hline $\begin{array}{c}\text { Neurodevelopmental } \\
\text { outcomes }\end{array}$ & $\begin{array}{c}\text { Extremely } \\
\text { Premature (less } \\
\text { than } 28 \text { weeks) }\end{array}$ & $\begin{array}{l}\text { Moderately } \\
\text { Premature (28 } \\
\text { to } 32 \text { weeks) }\end{array}$ & $\begin{array}{l}\text { Low Premature } \\
\text { (32 to } 37 \text { weeks) }\end{array}$ & $\begin{array}{l}\text { Term ( } 37 \text { weeks } \\
\text { onwards) }\end{array}$ & $\begin{array}{l}\text { Pearson Chi- } \\
\text { Square Statistic } \\
\text { and p-value }\end{array}$ & $\begin{array}{l}\text { Fisher's Exact } \\
\text { Test Statistic and } \\
\text { p-value }\end{array}$ \\
\hline \multicolumn{7}{|c|}{ Cognitive } \\
\hline Concerning & 3 & 1 & 6 & 1 & $\begin{array}{c}14.13 \\
\text { (p-value }=0.028)\end{array}$ & $\begin{array}{c}13.73 \\
\text { (p-value }=0.012 \text { ) }\end{array}$ \\
\hline Borderline & 0 & 2 & 0 & 0 & & \\
\hline Good & 1 & 22 & 13 & 3 & & \\
\hline \multicolumn{7}{|l|}{ Language } \\
\hline Concerning & 3 & 8 & 9 & 1 & $\begin{array}{c}7.368 \\
\text { (p-value }=0.268 \text { ) }\end{array}$ & $\begin{array}{c}6.105 \\
\text { (p-value }=0.383)\end{array}$ \\
\hline Borderline & 0 & 4 & 0 & 0 & & \\
\hline Good & 2 & 13 & 9 & 3 & & \\
\hline \multicolumn{7}{|l|}{ Motor } \\
\hline Concerning & 3 & 1 & 4 & 0 & $\begin{array}{c}15.32 \\
\text { (p-value }=0.020)\end{array}$ & $\begin{array}{c}11.068 \\
\text { (p-value }=0.041)\end{array}$ \\
\hline Borderline & 0 & 3 & 2 & 0 & & \\
\hline Good & 1 & 21 & 12 & 4 & & \\
\hline
\end{tabular}

Table 6: Neurodevelopmental outcomes and Birthweight.

\begin{tabular}{|c|c|c|c|c|c|c|}
\hline $\begin{array}{c}\text { Neurodevelopmental } \\
\text { outcomes }\end{array}$ & $\begin{array}{l}\text { Extremely Low } \\
\text { Birthweight }\end{array}$ & $\begin{array}{l}\text { Moderately Low } \\
\text { Birthweight }\end{array}$ & $\begin{array}{c}\text { Low } \\
\text { Birthweight }\end{array}$ & $\begin{array}{c}\text { Average } \\
\text { Birthweight }\end{array}$ & $\begin{array}{l}\text { Pearson Chi- } \\
\text { Square Statistic } \\
\text { and p-value }\end{array}$ & $\begin{array}{c}\text { Fisher's Exact } \\
\text { Test Statistic and } \\
\text { p-value }\end{array}$ \\
\hline \multicolumn{7}{|l|}{ Cognitive } \\
\hline Concerning & 2 & 2 & 6 & 1 & \multirow{3}{*}{$\begin{array}{c}8.075 \\
\text { (p-value }=0.213)\end{array}$} & \multirow{3}{*}{$\begin{array}{c}8.075 \\
\text { (p-value }=0.213)\end{array}$} \\
\hline Borderline & 1 & 1 & 0 & 0 & & \\
\hline Good & 2 & 14 & 15 & 7 & & \\
\hline \multicolumn{7}{|l|}{ Language } \\
\hline Concerning & 3 & 7 & 10 & 1 & \multirow{3}{*}{$\begin{array}{c}9.918 \\
(p-v a l u e=0.126)\end{array}$} & \multirow{3}{*}{$\begin{array}{c}9.266 \\
\text { (p-value }=0.106)\end{array}$} \\
\hline Borderline & 1 & 3 & 0 & 0 & & \\
\hline Good & 1 & 7 & 11 & 6 & & \\
\hline
\end{tabular}




\begin{tabular}{|c|c|c|c|c|c|}
\hline Motor & & & & \\
\hline Concerning & 3 & 1 & 4 & 0 & 14.091 \\
\hline Borderline & 1 & 1 & 3 & 0 & 14.091 \\
\hline Good & 1 & 15 & 13 & 8 & $(p-v a l u e=0.025)$ \\
\hline
\end{tabular}

Extreme prematurity occurred in $8 \%$ of the cohort, and this group had neurodevelopmental problems in $75 \%$, as can be seen in Figure 6 (IUD or NND in 50\%). Moderate prematurity was present in $47 \%$, with $28 \%$ having neurodevelopmental problems, and $12 \%$ either IUD or NND. Late prematurity ( $45 \%$ of the cohort) had $29 \%$ associated with neurodevelopmental problems, and a $16.7 \%$ death rate. Not only are the neurodevelopmental outcomes of premature twins concerning; there is also high incidence of intrauterine and neonatal deaths. Figure 6 shows the death rate for twins who were extremely premature (<28weeks), which was $50 \%$. This is significantly higher than those who were of moderate

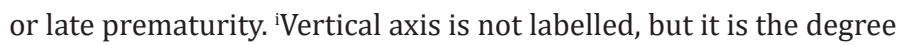
of abnormal neurodevelopment.

\section{Birth weight and Neurodevelopmental Outcomes}

This cohort was biased towards lower than average birthweight, due to factors such as twinning and monochorionic complications. For cognition, the Pearson chi-square test and the Fisher's Exact Test were not statistically significant $(p>0.05)$. However, for motor, the Pearson chi-square value was 14.091, and there was a p-value of 0.025 , thus statistically significant. The Fisher's Exact Test was also significant, with a value of 11.750 and a Fisher's Exact p-value of 0.026 .

\section{Discussion}

\section{Non-Monochorionic Complications}

There were a number of non-monochorionic related complications in the cohort. Common complications were Patent Ductus Arteriosus (PDA) and sepsis, which are both prevailing complications in preterm infants [42,43]. There were also a significant number of cerebral insults. The number of isolated cases of these conditions, (namely, that the other twin was not affected), is not unexpected in monochorionic complications, as the donor/ recipient relationship affects the twins differently [44-46].

\section{Developmental Outcomes}

The goal of this research was to investigate the relationship between time of diagnosis of monochorionic complications during pregnancy and future neurodevelopmental outcomes. The hypothesis was that prolonged exposure of the brain to blood flow abnormalities that occur in monochorionic complications increases the risk of abnormal neurodevelopmental outcomes. Haemodynamic imbalances associated with placental vascular anastomoses is thought to be associated with a cerebral insult, causing neurological impairment [7]. However, the hypothesis of this study was not supported by the results of this study design. In the pre-28-week group, $44.74 \%$ of the twins had concerning neurodevelopmental outcomes. This was statistically significant in comparison with overall neurodevelopmental outcomes in the post 28 -week group (21.40\%). The pre 28 week performed poorly in comparison to the post 28-week group, with means in motor and language being statistically different ( $p$-value $=0.044$ and p-value $=0.012$ respectively). 3 of the post 28 week group had language scores 2SD below the BSID-III mean, whilst 7 of the pre 28-week group had scores below 2SD, and 10 had scores less than 1SD.

Reflecting on past studies, this study delivered comparable results of concerning neurodevelopment in twins with monochorionic complications; $22 \%$ of a 40 -participant cohort had cerebral palsy and global cognitive delay [47]. Language and motor scores varied the most between the pre and post 28-week groups. The better outcomes in the post 28-week group can be explained through the greater number of acute and severe presentations in the pre-28-week group. Moreover, despite the risk of prolonged exposure to hemodynamic imbalance in pregnancies that are diagnosed after 28 weeks, the events that led to an acute instability and onset of Twin-Twin Transfusion (manifesting in an early, pre 28-week presentation), is likely to result in long term neurological effects. 23 Cases that present before 28 weeks are characteristically more severe and require more intensive treatment options. The higher level of prematurity that was in the pre-28-week group also affected this. Due to the increased severity of these cases, more intensive treatment is often required.

The better neurodevelopmental findings in the post 28-week Twin-Twin Transfusion group may be considered to support that the Twin-Twin Transfusion process is not chronic, but occurs acutely and if recognised and managed, then significant harm can be reduced. In most cases, this is achieved through delivery. Although complete prediction of future neurodevelopmental groups could not be achieved in this study as different neurodevelopmental tests were used at 8 months and 2 years, a correlation could be drawn between those who perform very poorly and those who perform very well in their future assessments. However, it is not possible to make a valid prediction for those in the 'middle' of the group.44 Poor results in an 8 month or 2 year 'concerning' was defined as a score that was below 75 for the BSID-III, or equivalent neurodevelopmental assessment does not necessarily mean that the child will have poor outcomes when they are older, but it does indicate that they will need more intensive support and possible intervention. That is why these neurodevelopmental tests are important, especially in twins affected by monochorionic complications [14,39,41].

\section{Comparison with the Neurodevelopmental Outcomes of the Twins in this study and those of Other Studies}

A study comparing the neurodevelopmental outcomes of twins and singletons born less than 34 weeks concluded that there was no significant difference in cognitive outcomes (referencing the BSID-III) of singletons compared with twins at 24 months [45]. The mean BSID-III cognitive and motor scores for the monochorionic complications cohort were comparable with the mean scores for DCDA twins and singletons (Table 7). Both studies had similar 
sample sizes and characteristics. The similarity in these results could be accounted for with the significant prematurity of the DCDA and singleton study.

Table 7: Comparison of this study's mean neurodevelopmental scores with those of another study.

\begin{tabular}{|c|c|c|c|}
\hline & $\begin{array}{c}\text { MCDA } \\
\text { complications } \\
\mathbf{( 4 1 )}\end{array}$ & $\begin{array}{c}\text { DCDA twins } \\
\mathbf{( 4 6 )}\end{array}$ & Singletons (46) \\
\hline $\begin{array}{c}\text { Cognitive Scale, } \\
\text { Mean }\end{array}$ & $97.7(+/-15.0)$ & $\begin{array}{c}98.6(+/-10.4) \\
{[45]}\end{array}$ & $\begin{array}{c}97.8(+/-9.7) \\
{[45]}\end{array}$ \\
\hline $\begin{array}{c}\text { Motor Scale, } \\
\text { Mean }\end{array}$ & $96.2(+/-12.5)$ & $\begin{array}{c}94.8(+/-12.4) \\
{[45]}\end{array}$ & $\begin{array}{c}98.1(+/-9.6) \\
{[45]}\end{array}$ \\
\hline
\end{tabular}

\section{Effect of Prematurity}

A factor that must be taken into account is that a very large proportion (47/53) of the participants had some degree of prematurity; and so their neurodevelopmental means were compared with a group of singletons of similar cohort factors and sample size. Prematurity had a sizeable effect on the neurodevelopmental outcomes assessed at 2 years. However, it is important to note that in this cohort, monochorionic complications have a strong effect bias towards prematurity.46 Pregnancy complications like Twin-Twin Transfusion decrease the gestational age because it is sometimes beneficial for the outcomes of the twins to deliver before term to limit the exposure to the condition. Other factors that may cause prematurity include cervical incompetence as a secondary cause (when associated with polyhydramnios) or a primary event associated with twins [47]. Prematurity had a sizeable effect on the neurodevelopmental outcomes assessed at 2 years, such as poor language development $[10,48]$. Of those with extreme prematurity, $75 \%$ had neurodevelopmental concerns. Statistical significance between prematurity and cognition and motor outcomes were shown.

This study also showed statistical significance between low birthweight and poorer motor outcomes. Treatment and Neurodevelopmental Outcomes: Conservative, Laser and Amniodrainage. Before laser treatment was available (during which amniodrainage was the main form of treatment for TTTS), $15.4 \%$ were diagnosed with CP. In comparatively, $8.5 \%$ of TTTS cases treated with laser were diagnosed with CP.21 Laser surgery has greatly reduced the rates of neurological disability; however, there are still marked neurological effects in those untreated. In terms of treatment options (of which there are three categories), this cohort was predominantly treated using conservative measures (49\%). This was because the cohort were not all TTTS Stage 2 or greater, where laser is considered the optimal elective treatment at less than 26 weeks [8]. Due to the neurodevelopmental effects of amniodrainage (particularly in increasing the rate of cerebral palsy), it was the least common form of treatment $(17 \%)$ as it only treats the effects and not the cause, especially in TTTS Stage 2 or greater [20]. Laser treatment was performed on $34 \%$ of the cohort. Interestingly, the twins who did not undergo treatment (were treated conservatively), had the most minimal neurological concerns (7.7\%). A confounding factor for this could be that those who were not treated with Amniodrainage or Laser were less severe cases of monochorionic complications.

\section{Limitations and Further Research}

There were a number of limitations identified in this study. Language, motor and cognitive facets were the only areas that were assessed, rather than the adaptive and behavioural components of the BSID-III assessment in the interest of practicality and time resources available [13]. Confounding factors include the demographic of the population, as Liverpool hospital caters to a diverse multicultural area, where English is often a second language [49]. However, this would ideally have been offset by the utilisation of the Rossetti Language Schema alongside the BSID-III Language evaluation, which primarily is designed for 'English as a first language' children. A common setback in neurodevelopmental tests for infants and toddlers is non-compliance in the testing scenario, as the participants generally have a lot of restless energy and a short attention span [44]. The BSID-III can be performed at 8 months, but the MAI is preferred as it is a more holistic portrayal of motor outcomes. Similarly, the Rossetti provides results for a very broad population. The difference in assessment mediums between 8 months and 2 years was reasoned due to issues with performing the BSID-III assessments at 8 months.

Thus, only the Rossetti language test and the MAI was performed. Assessment of the neurodevelopmental outcomes at later stages would be ideal, as many neurodevelopmental concerns do not present until school age. Another important limitation of this study is the apparent lack of correlation between 2 year BSID-III scores and 4.5 year scores, reported in a cohort study.41 Moreover, although developmental outcomes are often interpreted as 'concerning' or 'good', an ideal approach would include 'a continuum of ability'50 It is well understood that neurodevelopmental outcomes can vary greatly over time, and so a longer study period would be ideal to remedy this. A larger sample size would also be beneficial, and a control group to compare results. The heterogeneity of the group was also a concern; as there was a variety of different monochorionic complications. Although gestational age comparison was performed, the hypothesis that the earlier the diagnosis of Twin-Twin Transfusion (thus the longer the interval to delivery) translated to a longer exposure to hemodynamic imbalance is not valid in those cases that had laser treatment.

Laser treatment immediately creates a dichorionic placenta, as there are ideally no anastomoses. Placental share may also be aggravated other confounders in the TTTS laser treated group. This issue was not addressed. Moreover, the influence of prematurity was arguably undermined by excluding TTTS cases who delivered before 28 weeks. Further research into the particular factors that affect neurodevelopmental outcomes of twins needs to be performed. With a larger sample size and a longer follow up period, important conclusions could be made about the effect of time of diagnosis on neurodevelopmental outcomes.

\section{Conclusion}

This study aimed to investigate the effect that time of diagnosis had on neurodevelopmental outcomes of twins complicated by monochorionicity. It concluded that those diagnosed before 28 weeks generally had poorer language and motor outcomes than 
those diagnosed after 28 weeks. Proactive management and treatment of monochorionic complications as soon as possible is thus recommended.

\section{Statement of Contribution}

The creation of this study is attributed to Dr John Smoleniec (John.Smoleniec@sswahs.nsw.gov.au) and Dr Jacqueline Stack, who made contributions to the conception of the study methodology, data collection/analysis and the final paper. Data collection, analysis and manuscript development was completed by medical student Erica Longhurst (z5075764@ad.unsw.edu.au). Antenatal results were recorded by Dr John Smoleniec, and neurodevelopmental testing was performed by Dr Jacqueline Stack (Jacqueline.Stack@health. nsw.gov.au), Dr Rodney Tobiansky and Dr John Levison. Statistical assistance was provided by Dr Boaz Shulruf.

\section{Ethics Approval}

Ethics approval was attained from a request in 2009 to perform an ongoing conjoint project with the Liverpool Fetomaternal Unit (FMU) and the Rainbow Cottage Clinic. This study had ethical approval from the Human Research Ethics Committees of the South Western Sydney Area Health Service (EC00136) and the University of New South Wales.

\section{References}

1. Corsello G, Piro E (2010) The world of twins: an update. The journal of maternal-fetal \& neonatal medicine : the official journal of the European Association of Perinatal Medicine, the Federation of Asia and Oceania Perinatal Societies, the International Society of Perinatal Obstet 23(3): 59-62.

2. Hack KE, Derks JB, Elias SG, Franx A, Roos EJ, et al. (2008) Increased perinatal mortality and morbidity in monochorionic versus dichorionic twin pregnancies: clinical implications of a large Dutch cohort study. BJOG:an international journal of obstetrics and gynaecology 115(1): 5867.

3. Al Riyami N, Al Rusheidi A, Al Khabori M (2013) Perinatal Outcome of Monochorionic in Comparison to Dichorionic. Twin Pregnancies. Oman Medical Journal 28(3): 173-177.

4. Adegbite AL, Castille S, Ward S, Bajoria R (2004) Neuromorbidity in preterm twins in relation to chorionicity and discordant birth weight. Am J Obstet Gynecol 190(1): 156-163.

5. Ortibus E, Lopriore E, Deprest J, Vandenbussche FP, Walther FJ, et al (2009) The pregnancy and long-term neurodevelopmental outcome of monochorionic diamniotic twin gestations: a multicenter prospective cohort study from the first trimester onward. Am J Obstet Gynecol 200(5): 494.e1-8.

6. Obiechina NJ, Okolie VE, Eleje GU, Okechukwu ZC, Anemeje OA (2011) Twin versus singleton pregnancies: the incidence, pregnancy complications, and obstetric outcomes in a Nigerian tertiary hospital. International Journal of Women's Health 3: 227-230.

7. Pharoah POD, Adi Y (2000) Consequences of in-utero death in a twin pregnancy. The Lancet 355(9215): 1597-1602.

8. Rossi AC, Vanderbilt D, Chmait RH (2011) Neurodevelopmental outcomes after laser therapy for twin-twin transfusion syndrome: a systematic review and meta-analysis. Obstetrics \& Gynecology 118(5): 1145-1150.

9. Kevat D, Mackillop L (2013) Neurological diseases in pregnancy. The Journal of the Royal College of Physicians of Edinburgh 43(1): 49-58.

10. Pharoah P (2002) Neurological outcome in twins. Seminars in neonatology: SN 7(3): 223-230.
11. Lee CM, Yang SH, Lee SP, Hwang BC, Kim SY (2014) Clinical factors affecting the timing of delivery in twin pregnancies. Obstetrics \& Gynecology Science 57(6): 436-441.

12. Glinianaia SV, Rankin J, Wright C (2008) Congenital anomalies in twins: a register-based study. Human reproduction (Oxford, England) 23(6): 1306-1311.

13. Hack KE, Koopman Esseboom C, Derks JB, Elias SG, De Kleine MJ, et al. (2009) Long-term neurodevelopmental outcome of monochorionic and matched dichorionic twins. PLoS One 4(8): e6815.

14. Sierakowski A, Eapen V, Crncec R, Smoleniec J (2017) Developmental and behavioral outcomes of uncomplicated monochorionic diamniotic twins born in the third trimester. Neuropsychiatr Dis Treat 13: 13731384.

15. Dickinson JE, Duncombe GJ, Evans SF, French NP, Hagan R (2005) The long-term neurologic outcome of children from pregnancies complicated by twin-to-twin transfusion syndrome. BJOG 112(1): 63-68.

16. Walker SP, Cole SA, Edwards AG (2007) Victorian Fetal Therapy S Twinto-twin transfusion syndrome: Is the future getting brighter? Australian and New Zealand Journal of Obstetrics and Gynaecology 47(3): 158-168.

17. Wagner S, Repke JT, Ural SH (2013) Overview and Long-term Outcomes of Patients Born With Twin-to-Twin Transfusion Syndrome. Reviews in Obstetrics and Gynecology 6(3-4): 149-154.

18. Couck I, Lewi L (2016) The Placenta in Twin-to-Twin Transfusion Syndrome and Twin Anemia Polycythemia Sequence. Twin Research and Human Genetics 19(3): 184-190.

19. Campos D, Arias AV, Campos Zanelli TM, Souza DS, Dos Santos Neto OG, et al. (2016) Twin-twin transfusion syndrome: neurodevelopment of infants treated with laser surgery. Arquivos de neuro-psiquiatria 74(4): 307-313.

20. Sananès N, Gabriele V, Weingertner AS, Ruano R, Sanz Cortes M, et al. (2016) Evaluation of long-term neurodevelopment in twin-twin transfusion syndrome after laser therapy. Prenatal diagnosis 36(12): 1139-1145.

21. Odibo AO, Caughey AB, Grobman W, Stamilio DM, Ville Y (2009) Selective laser photocoagulation versus serial amniodrainage for the treatment of twin-twin transfusion syndrome: a cost-effectiveness analysis. Journal of perinatology : official journal of the California Perinatal Association 29(8): 543-547.

22. Lenclen R, Ciarlo G, Paupe A, Bussieres L, Ville Y (2009) Neurodevelopmental outcome at 2 years in children born preterm treated by amnioreduction or fetoscopic laser surgery for twin-to-twin transfusion syndrome: comparison with dichorionic twins. American Journal of Obstetrics \& Gynecology 201(3): 291e1-. e5.

23. Lewi L, Deprest J, Hecher K (2013) The vascular anastomoses in monochorionic twin pregnancies and their clinical consequences. Am J Obstet Gynecol 208(1): 19-30.

24. Tan TY, Denbow ML, Cox PM, Talbert D, Fisk NM (2004) Occlusion of arterio-arterial anastomosis manifesting as acute twin-twin transfusion syndrome. Placenta 25(2-3): 238-242.

25. Sebire NJ, Souka A, Skentou H, Geerts L, Nicolaides KH (2000) Early prediction of severe twin-to-twin transfusion syndrome. Human Reproduction 15: 2008-2010.

26. F Slaghekke, HM Koopman, JM Middlemorp, D Oepkes, E Lopoire (2014) Neurodevelopmental outcome in twin anemia-polycythemia sequence after laser surgery for twin-twin transfusion syndrome. Ultrasound Obstetric Gynecology 44(3): 316-321.

27. Graef C, Ellenrieder B, Hecher K, Hackeloer BJ, Huber A, et al. (2006) Long-term neurodevelopmental outcome of 167 children after intrauterine laser treatment for severe twin-twin transfusion syndrome. American Journal of Obstetrics \& Gynecology 194(2): 303-308.

28. Salt A, Redshaw M (2006) Neurodevelopmental follow-up after preterm birth: follow up after two years. Early Human Development 82(3): 185197. 
29. Msall ME (2006) Neurodevelopmental surveillance in the first 2 years after extremely preterm birth: evidence, challenges, and guidelines. Early human development 82(3): 157-166.

30. Rand L, Lee H (2009) Complicated monochorionic twin pregnancies: updates in fetal diagnosis and treatment. Clinics in perinatology 36(2): 417-430, x-xi.

31. Lewi L (2010) Monochorionic diamniotic twin pregnancies pregnancy outcome, risk stratification and lessons learnt from placental examination. Verhandelingen-Koninklijke Academie voor Geneeskunde van Belgie 72(1-2): 5-15.

32. Albers CA, Grieve AJ Test review: Bayley N (2006) Bayley scales of infant and toddler development-third edition. San Antonio, TX: Harcourt assessment. Journal of Psychoeducational Assessment 25: 180-90.

33. Barigye O, Pasquini L, Galea P, Chambers H, Chappell L, et al. (2005) High Risk of Unexpected Late Fetal Death in Monochorionic Twins Despite Intensive Ultrasound Surveillance: A Cohort Study. PLoS Medicine 2(6): e172.

34. Carroll SG, Soothill PW, Abdel Fattah SA, Porter H, Montague I, et al. (2002) Prediction of chorionicity in twin pregnancies at 10-14 weeks of gestation. Bjog 109(2): 182-186.

35. Spittle A (2008) A systematic review of the clinimetric properties of neuromotor assessments for preterm infants during the first year of life. Elon university.

36. Harris SR, Swanson MW, Andrews MS, Sells CJ, Robinson NM, et al (1984) Predictive validity of the Movement Assessment of Infants. Journal of Developmental and Behavioral Pediatrics 3(1): 19-23.

37. Rossetti L (2006) The Rossetti Infant-Toddler Language Scale: lingui Systems.

38. Eun Young P, Won Ho K (2015) Relationship between the Gross Motor Function Classification System and Functional Outcomes in Children with Cerebral Palsy. Indian Journal of Science and Technology 8(18).

39. Picciolini O, Squarza C, Fontana C, Gianni ML, Cortinovis I, et al. (2015) Neurodevelopmental outcome of extremely low birth weight infants at 24 months corrected age: a comparison between Griffiths and Bayley Scales. BMC Pediatr 15: 139.

40. Luttikhuizen dos Santos ES, de Kieviet JF, Königs M, van Elburg RM, Oosterlaan J (2013) Predictive value of the Bayley Scales of Infant Development on development of very preterm/very low birth weight children: A meta-analysis. Early Human Development 89(7): 487-496.

\section{ISSN: 2574-1241}

DOI: 10.26717/BJSTR.2019.16.002922

Longhurst E. Biomed J Sci \& Tech Res

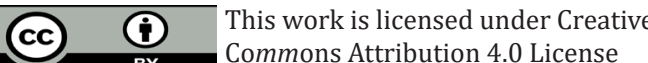

Submission Link: https://biomedres.us/submit-manuscript.php
41. Burakevych N, Mc Kinlay CJD, Alsweiler JM, Wouldes TA, Harding JE (2017) Bayley-III motor scale and neurological examination at 2 years do not predict motor skills at 4.5 years. Developmental medicine and child neurology 59(2): 216-223.

42. Benitz WE (2016) Patent Ductus Arteriosus in Preterm Infants. Pediatrics 137(1).

43. Mai V, Torrazza RM, Ukhanova M, Wang X, Sun Y, et al. (2013) Distortions in development of intestinal microbiota associated with late onset sepsis in preterm infants. PloS one 8(1): e52876.

44. Shapiro Bruce K (2011) Academic underachievement: A neurodevelopmental perspective. Revista Médica Clínica Las Condes 22 : 211-217.

45. Maria Kyriakidou PK, Zoi Iliodromiti, Ilias Chatziioannidis, Eleni Papaioannou, Sotiria Exadaktilou, et al. (2013) Comparison of 24 months neurodevelopmental outcome in twins and singletons $\leq 34$ weeks gestation at birth. Journal of Pediatric and Neonatal Individualized Medicine 2(1): 48-54.

46. Lenclen R, Paupe A, Ciarlo G, Couderc S, Castela F, et al. (2007) Neonatal outcome in preterm monochorionic twins with twin-to-twin transfusion syndrome after intrauterine treatment with amnioreduction or fetoscopic laser surgery: comparison with dichorionic twins. Am J Obstet Gynecol 196(5): 450.e1-7.

47. Hua W, Wei Z, Ling F, Song Y, Jian Rong M, et al. (2014) Effects of Maternal Cervical Incompetence on Morbidity and Mortality of Preterm Neonates with Birth weight Less than 2000g. Iranian Journal of Pediatrics 24(6): 759-65.

48. Van Klink JMM, Koopman HM, Steggerda SJ, Oepkes D, Rijken M, et al. (2013) Cerebral Injury and Neurodevelopmental Outcome in Twin-Twin Transfusion Syndrome. Current Obstetrics and Gynecology Reports 2: 240-248.

49. Ferfolja T, Vickers M (2010) Supporting refugee students in school education in Greater Western Sydney. Critical Studies in Education 51(2): 149-162.

50. Accardo P, Accardo J, Capute A (2008) A neurodevelopmental perspective on the continuum of developmental disabilities. Capute and Accardo's neurodevelopmental disabilities in infancy and childhood $3^{\text {rd }}$ ed Baltimore: Paul H Brookes, p. 3-26.

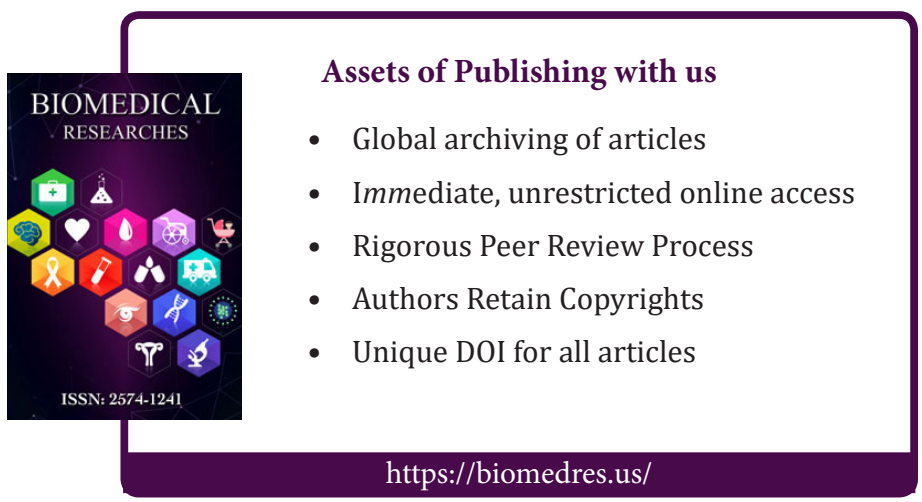

